\title{
Does economic freedom increase income inequality? Evidence from the EU countries
}

\author{
Salvador Pérez-Moreno ${ }^{1}$ \\ María J. Angulo-Guerrero
}

\begin{abstract}
Over the past decades there have been considerable changes in policies and institutions in favor of economic freedom in the EU countries. This trend coincides with widespread increases in income inequality in numerous member states. To what extent does economic freedom encourage inequality? This paper examines the relationship between economic freedom and income inequality in the EU countries using panel data for the 2000s. The empirical evidence suggests that economic freedom seems to entail greater income inequality. However, not all areas of economic freedom affect income distribution similarly. While government size and regulation appear to be robustly associated with income inequality, legal system and property rights, sound money, and freedom to trade internationally seem not to be significantly related with income distribution in the European context.
\end{abstract}

Keywords: Economic freedom; Income inequality; European Union

JEL Classification: C82, D31, E02

\footnotetext{
${ }^{1}$ University of Malaga, Department of Applied Economics (Economic Policy). Campus El Ejido, 29071, Malaga (Spain). Phone: +34-952131280. Fax: +34-952131283. E-mail: sperezmoreno@uma.es

2 University of Malaga, Department of Business Management. Campus El Ejido, 29071, Malaga (Spain). Phone: +34-952132692. Fax: +34-952131293. E-mail: mjanguloguerrero@uma.es
} 